\title{
The Effect of Maximal Exercise on Matrix Metalloproteinase, its Inhibitor (MMP9 and TIMP1), and the Role of MMP9-1562 C/T and TIMP1 372 T/C Polymorphisms
}

\section{Merve Koca Kosova ( $\nabla$ merve.koca@deu.edu.tr)}

Dokuz Eylul University: Dokuz Eylul Universitesi https://orcid.org/0000-0003-0454-2790

\section{Faruk Turgay}

Ege University: Ege Universitesi

Oya Yigittürk

Ege University: Ege Universitesi

\section{Semih Aşıkovalı}

Ege University: Ege Universitesi

\section{Sercin Kosova}

Dokuz Eylul University: Dokuz Eylul Universitesi

\section{Aykut Eren Canüzmez}

Ege University: Ege Universitesi

\section{Burak Durmaz}

Ege University: Ege Universitesi

\section{Research Article}

Keywords: enzymes, genetic polymorphisms, athletes, sedantaries, acute exercise, MMP9, TIMP1

Posted Date: March 19th, 2021

DOI: https://doi.org/10.21203/rs.3.rs-313259/v1

License: (a) (i) This work is licensed under a Creative Commons Attribution 4.0 International License. Read Full License 


\section{Abstract}

To investigate the levels of MMP9 and TIMP1 before and after acute maximal exercise and the role of MMP9-1562 C/T and TIMP1 $372 \mathrm{~T} / \mathrm{C}$ polymorphisms in athletes and sedentary individuals. The athlete group $(n=43)$ and sedentary group $(n=43)$ performed the Yo-Yo intermittent recovery test level 1. A blood sample was taken before and after the test. MMP9, TIMP1, MMP9/TIMP1 ratio, blood lipids, and lipoproteins (total cholesterol, high and low-density lipoprotein cholesterol) and indicators of muscle damage (creatine kinase, aspartate aminotransferase, alanine aminotransferase) were determined from postprandial venous blood samples. Genetic polymorphisms were determined from DNA samples obtained from peripheral blood. MMP9 levels were found higher in both groups after the YOYO IR-1 test (exercise) (sedentary group, pre-exercise: $1771.15 \pm 862.17 \mathrm{pg} / \mathrm{mL}$, post-exercise: $2172.18 \pm 680.93$ $\mathrm{pg} / \mathrm{mL}$; athletic group, pre-exercise: $1373.57 \pm 705.16 \mathrm{pg} / \mathrm{mL}$, post-exercise: $1723.72 \pm 733.88 \mathrm{pg} / \mathrm{mL}, \mathrm{p}<$ 0.05). TIMP1 levels were also found higher in both groups after exercise (sedentary group, pre-exercise: $4.63 \pm 3.99 \mathrm{ng} / \mathrm{mL}$, post-exercise: $5.3 \pm 3.51 \mathrm{ng} / \mathrm{mL}$; athletic group, pre-exercise: $3.26 \pm 2.34 \mathrm{ng} / \mathrm{mL}$, postexercise: $3.59 \pm 1.99 \mathrm{ng} / \mathrm{mL}, \mathrm{p}<0.05)$. Basal serum MMP9 levels were significantly higher in sedentary individuals as compared with athletes $(p=0.046)$. MMP9 $-1562 \mathrm{C} / \mathrm{T}$ and TIMP1 $372 \mathrm{~T} / \mathrm{C}$ polymorphisms had no effect on MMP9 and TIMP1 levels $(p>0.05)$. As a conclusion acute exercise increases MMP9 and TIMP1 levels in male athletes and sedentary individuals. Chronic anaerobic exercises performed by the athletic group may caused lower MMP9 levels. MMP9-1562 C/T and TIMP1 372 T/C genetic polymorphisms are not associated with MMP9 and TIMP1 activation.

\section{Introduction}

Organs and tissues receive structural support from extracelluler matrıx (ECM) which has a quite complex structure With hundred of proteins in the ECM, it takes part in the survival, differentiation, proliferation, and migration of cells [1]. Matrix metalloproteinases (MMPs) and tissue inhibitor of metalloproteinases (TIMPs) work together in ECM functions. MMPs have critical roles in degrading ECM components [2]. Among the 23 different MMPs found in humans [3], MMP2 and MMP9 have vital roles in ECM remodelling and muscle regeneration, and they are also involved in inflammatory reactions [4]. Because of pathological conditions in remodelling process MMP9 activity also associated with certain disease and many studies have been conducted investigating these relationships [5, 6]. Four TIMPs found in humans are endogenous inhibitors of MMPs and all TIMPs have some specificities for their inhibition function. They are effective in cellular behaviour, tissue remodelling, and the regulation of ECM turnover [7]. The expression of TIMPS happens at the transcriptional level. MMPs interact with TIMPS by forming 1:1 complexes [8]. Balance in the operation of MMPs and TIMPs is required for ECM function [4], especially after situations that can cause damage, such as acute exercise.

Exercise can affect the synthesis and degradation of collagen, which is found in large amounts in the human body [9]. MMP9 is largely attendant in the degradation of type IV collagen and many other types of collagen. Type IV collagen is the main ingredient of the basal lamina, which is a thin layer separating the epithelium from connective tissue [2]. For these reasons, one of the most frequently investigated 
markers among MMPs in exercise and human studies can be specified as MMP9. Many studies in the literature examined MMP9 and TIMP1 activity together $[10,11]$ because TIMP1 is secereted in association with MMP9 [12]. Expression of TIMP1 is actualized in numerous mammalian tissues [8] and it can be regulated by different cytokines or soluble factors in respect of cell types [13].

Researchers have studied the effect of exercise on MMP9 and TIMP1 [14, 15]. Mackey, Donnelly [9] investigated the effect of $10 \mathrm{~km}$ running and 50 minutes deep water running on healthy adults and found no significant change in serum MMP9 and TIMP1 levels after these exercises. In another study, individuals who had training experience and sedentary individuals performed downhill running. They found an increase in MMP9 levels in both groups and this increase remained in the sedentary individuals for the next four days [16]. Koskinen, Höyhtyä [17] found higher MMP9 and TIMP1 concentrations at different temperatures after eccentric exercise. Serum MMP9 concentrations increased after marathon and half maraton race on amateur athletes. However, the increase in marathon athletes was significantly higher than in half marathon athletes [18]. The disparity between studies may be related to many reasons such as exercise duration, exercise type, and the training history of the participants.

The MMP9-1562 C/T polymorphism (rs3918242) is a single nucleotide polymorphism at position - 1562, caused by the replacement of cytosine (C) with thymine (T) [19]. The TIMP1 gene is located on the $X$ chromosome and has 6 exons. The TIMP1372 T/C (rs4898) polymorphism is located on exon 5 [20]. Both polymorphisms have been studied in different disease groups and researchers have found relationships between these polymorphisms and some diseases [21, 22]. Investigating the polymorphism of the specified enzyme and its inhibitor may provide critical benefits to the literature while interpreting the possible effects of exercise on MMP9 and TIMP1 concentrations. However, the role of these polymorphisms in acute or chronic exercise-dependent MMP9 and TIMP1 concentration changes are unknown. The aim of the study was to investigate the levels of MMP9 and TIMP1 before and after acute maximal exercise and the role of MMP9-1562 C/T and TIMP1 $372 \mathrm{~T} / \mathrm{C}$ polymorphisms in athletes and sedentary participants.

\section{Materials And Methods}

There were two different groups in the study. The athletic group included 43 male basketball, volleyball, and handball players (mean age: $20.65 \pm 2.46$ years, height: $189.8 \pm 7.22 \mathrm{~cm}$, bodyweight: $87.32 \pm 14.1$ $\mathrm{kg}$ ), and the sedentary group included 43 healthy men (mean age: $22.49 \pm 3.51$ years, height: $178.63 \pm$ $7.46 \mathrm{~cm}$, bodyweight: $76.77 \pm 11.63 \mathrm{~kg}$ ). The athletic group consisted of individuals aged 18-35 years who had been training regularly for at least 3 months. They had been doing sport for a mean $9.87 \pm 3.71$ years. The sedentary group consisted of healthy individuals with similar physical characteristics to the athletes and the same age range, but who had not peformed regular exercise for at least 3 months.

The criteria for inclusion in the study were that the participants were not obese [body mass index (BMI) < $30 \mathrm{~kg} / \mathrm{m}^{2}$ ] and did not use tobacco-related products, alcohol, drugs, and antioxidants. All athletes were 
instructed to stop training 2 days before the measurements. All participants were instructed to continue their usual nutrition habits and to attend for measurements with four hours of fasting.

The research was approved by Ege University Faculty of Medicine Clinical Research Ethics Committee (Approval number: 18 - 7.1/49).

All participants were informed about the study and written informed consent was obtained before taking the measurements.

The height and body weight measurements of the participants were performed using a portable height measuring device and digital scales (Seca, Germany). BMI was calculated using the following formula: $\mathrm{BMI}=$ Weight $(\mathrm{kg}) /$ height $\left(\mathrm{m}^{2}\right)$. All participants performed a standard warm-up procedure. The procedure consisted of the first 4 speed levels of the Yo-Yo Intermittent Recovery Test level 1 (Yo-Yo IR1), dynamic stretching, basic running, and change of direction exercises.

The Yo-Yo IR1 was applied to all participants as an acute maximal exercise after standard warming up. It is a standard test that includes running periods $(20 \times 2=40 \mathrm{~m})$ with gradually increasing speeds. Active rest is performed by walking or jogging at a distance of $10 \mathrm{~m}(2 \times 5)$ for 10 seconds after every $40 \mathrm{~m}$ run. The Yo-Yo IR1 lasts 10-20 minutes depending on the ability level of the participants [23]. The test was continued until the participants were exhausted. The distance that they could not continue and their heart rate during this time were recorded. If the participants could not complete the $40 \mathrm{~m}$ distance despite the auditory signal and this situation occurred twice consecutively, the test was ended for these participants by the researchers.

A blood sample was taken 20-25 minutes before and 10 minutes after the Yo-Yo IR1. MMP9, TIMP1, MMP9/TIMP1 ratio, blood lipids and lipoproteins [total cholesterol (TC), high and low-density lipoprotein cholesterol (HDL-C and LDL-C)] and indicators of muscle damage [creatine kinase (CK), aspartate aminotransferase (AST), alanine aminotransferase (ALT)] were determined from postprandial venous blood samples. Blood samples were kept at room temperature for 20 minutes, then centrifuged at $2000 \mathrm{~g}$ for 15 minutes and their serums were separated. Serum samples were stored at $-82^{\circ} \mathrm{C}$ until required for further analysis. CK, AST, and ALT activities, TC, HDL-C and LDL-C were assessed using standard enzymatic-colorimetric methods with an autoanalyzer (Roche Cobas 8000, Switzerland). Serum MMP9 and TIMP1 levels were determined using enzyme-linked immunosorbent assay (ELISA) by measuring at $450 \mathrm{~nm}$ on a microplate reader (Dialab ELx800, Austria). Commercial kits (Human ELISA Kit Elabscience, USA) were used for these procedures. The MMP9/TIMP1 ratio was calculated using the molecular weight of MMP9 (92kDa) and TIMP1 (28kDa).

MMP9-1562 C/T and TIMP1 $372 \mathrm{~T} / \mathrm{C}$ polymorphisms were determined from DNA samples isolated from peripheral blood leukocytes using standard techniques according to the manufacturer's (QIAGEN®-Hilden, Germany) instructions. Polymerase chain reaction (PCR) and restriction fragment length polymorphism (RFLP) was used for the determination of genotypes. The primers used were 5'GCCTGGCACATAGTAGGCCC-3' (forward) and 5'-CTTCCTAGCCAGCCGGCATC-3' (reverse) for the MMP9 
gene; 5'-GCACATCACTACCTGCAGTC-3' (forward) and 5'-GAAACAAGCCCACGATTTAG-3' (reverse) for the TIMP1 gene. PCR components used per sample were as follows: $11.5 \mu \mathrm{L}$ of $\mathrm{DdH}_{2} \mathrm{O}, 2.5 \mu \mathrm{L}$ of $10 \mathrm{X} \mathrm{PCR}$ buffer, $1 \mu \mathrm{L}$ of dNTP mix, $2 \mu \mathrm{L}$ of $\mathrm{MgCl}_{2}, 1.25 \mu \mathrm{L}$ of forward primer, $1.25 \mu \mathrm{L}$ of reverse primer, $0.5 \mu \mathrm{L}$ of Taq polymerase, $5 \mu \mathrm{L}$ of DNA, $25 \mu \mathrm{L}$ in total. The reaction conditions for amplification were as follows: $95^{\circ} \mathrm{C}$ for $5 \mathrm{~min} ; 30$ cycles of $95^{\circ} \mathrm{C}$ for $45 \mathrm{~s}$, primer annealing for $45 \mathrm{~s}$, and $72^{\circ} \mathrm{C}$ for $45 \mathrm{~s}$; and a final extension at $72^{\circ} \mathrm{C}$ for $5 \mathrm{~min}$. The primer annealing temperature was set to be $61^{\circ} \mathrm{C}$ for the $M M P$ gene and $54.5^{\circ} \mathrm{C}$ for the TIMP1 gene. Following amplification, the PCR products (MMP9's $436 \mathrm{bp}$, TIMP1's $175 \mathrm{bp}$ ) were digested with the restriction endonuclease (MMP9-Sphl, TIMP1-BssSI). Fragments were separated through electrophoresis in $6 \%$ agarose gel at $100 \mathrm{~V}$ for $120 \mathrm{~min}$ and visualized using ultraviolet transillumination after ethidium bromide staining. A single band at $436 \mathrm{bp}$ represented $\mathrm{C}$ homozygous, two bands at 194-242 represented T homozygous, and three bands at 294-242-436 bp represented heterozygous for MMP gene. For the TIMP1 gene, a single band at $175 \mathrm{bp}$ represented T hemizygous, and two bands at 20-155 bp represented $C$ hemizygous. Additionally, $10 \%$ of the samples were sequenced using a next-generation system (Nextseq) to confirm the genotyping results.

Statistical analyses were performed using SPSS (IBM SPSS Statistics for Windows, version 24.0. Armonk, NY). Results are presented mean \pm standard deviation except in the tables, and $p<0.05$ was considered for significant statistical difference. According to the results of the normality test (Shapiro-Wilk test), comparisons of physical and physiologic characteristics and comparisons of the measurements of the groups before acute exercise were performed using the Mann-Whitney $U$ test. Comparisons of the measurements before and after the acute exercise in the same group were performed using the Wilcoxon test. Genotype and allele frequencies were calculated using the Hardy-Weinberg equation. Comparisons of genotype frequencies of the sedentary and athletic groups were performed using the Pearson Chisquare test. Comparison of the pre- and post-exercise measurements of the sedentary and athletic groups according to MMP9-1562 C/T and TIMP1 372 T/C polymorphism genotypes was performed using threeway repeated-measures analysis of variance (ANOVA) [exercise (pre/post Yo-Yo IR1) x group (sedentary/athlete) x polymorphism genotype/allele group].

\section{Results}

There was no statistically significant difference in terms of BMI between the sedentary and athletic groups ( $p>0.05$ ). The BMI results of both groups were found within normal values (sedentary: $23.99 \pm 2.73$, athletic: $24.17 \pm 3.2)$. The mean $\mathrm{VO}_{2} \mathrm{Max}$ levels of the athletic group were significantly better $(45.54 \pm 4.06$ $\mathrm{mL} / \mathrm{kg} / \mathrm{min})$ compared with the sedentary group $(43.37 \pm 2.3 \mathrm{~mL} / \mathrm{kg} / \mathrm{min}, \mathrm{p}=0.037)$.

In the sedentary group, serum MMP9 levels were higher after acute exercise (pre-exercise: $1771.15 \pm 862.17 \mathrm{pg} / \mathrm{mL}$ 95\% confidence interval (Cl): [1505.81-2036.48; post-exercise: $2172.18 \pm 680.93$ pg/mL, 95\% Cl: [1962.62-2381.74]; $\mathrm{p}<0.001$. Serum TIMP1 levels were higher after acute exercise (preexercise: $4.63 \pm 3.99 \mathrm{ng} / \mathrm{mL}, 95 \%$ Cl: [3.41-5.86], post-exercise: $5.3 \pm 3.51 \mathrm{ng} / \mathrm{mL}, 95 \%$ Cl: [4.22-6.38]; $p=0.005)$. For the MMP9/TIMP1 ratio, no differences were found in pre-exercise and post-execise levels $(p>0.05)$. 
In the athletic group, serum MMP9 levels were higher after acute exercise (pre-exercise: $1373.57 \pm 705.16$ pg/mL, 95\% Cl: [1156.55-1590.58], post-exercise: 1723.72 \pm 733.88 pg/mL, 95\% Cl: [1497.87-1949.58]; p 0.001 ). Serum TIMP1 levels were higher after acute exercise (pre-exercise: $3.26 \pm 2.34 \mathrm{ng} / \mathrm{mL}, 95 \% \mathrm{Cl}$ : [2.54-3.98], post-exercise: $3.59 \pm 1.99 \mathrm{ng} / \mathrm{mL}, 95 \% \mathrm{Cl}$ : [2.98-4.21]; $p=0.005)$. Regarding the MMP9/TIMP1 ratio, no differences were found in pre-exercise and post-execise levels $(p>0.05)$.

According to the pre-exercise levels, serum MMP9 levels were higher in the sedentary group compared with the athletic group $(p=0.046)$. Serum TIMP1 and MMP9/TIMP1 ratio levels were not statistically different in the sedentary and athletic groups ( $p>0.05)$.

No statistically significant difference was found between the polymorphism and allelic frequencies of the sedentary and athletic groups $(\mathrm{p}>0.05)$ (Table 1$)$. For the MMP9-1562 C/T polymorphism, it was determined that genotype and any interaction with genotype had no statistically significant effect on the MMP9 and TIMP1 levels ( $p>0.05)$. It was determined that the effect of exercise, group, and genotype interaction on AST was statistically significant. The increase in post-exercise AST levels was higher in athletes with the CT genotype than in sedentary individuals with the CT genotype. The comparison of all parameters of sedentary individuals and athletes before and after the exercise belonging to the MMP9-1562 C/T polymorphism genotype groups are presented in Table 2. For the TIMP1 $372 \mathrm{~T} / \mathrm{C}$ polymorphism, it was determined that the allele and any interaction with the allele had no statistically significant effect on MMP9 and TIMP1 levels ( $p>0.05)$. The TIMP1 372 T/C polymorphism had a significant effect on TC and LDL-C levels and individuals with $C$ alleles had higher TC and LDL-C levels than in individuals with $T$ alleles. The effect of exercise and allele interaction on LDL-C was found statistically significant. The amount of increase of LDL-C was higher in individuals with $\mathrm{C}$ alleles than in individuals with $\mathrm{T}$ alleles. The comparison of parameters of the sedentary and athletic groups before and after the exercise belonging to the TIMP1372 T/C polymorphism allele groups are shown in Table 3 .

\section{Discussion}

The main findings of this study showed that MMP9 and TIMP1 levels increased after acute exercise in both the sedentary and athletic groups. The present findings also suggested that pre-exercise MMP9 levels of athletes were lower compared with the sedentary individuals. Our findings revealed that the MMP9-1562 C/T and TIMP1 372 T/C polymorphisms and the interaction of polymorphisms with other parameters, i.e. exercise and group, did not significantly affect MMP9 and TIMP1 levels.

In line with the current findings, Astill, Katsma [24] investigated the effects of acute resistance exercise on certain parameters including MMP9 and TIMP1. They found significantly higher MMP9 levels in male participants two hours after exercise. TIMP1 levels increased in both male and female participants and this increase in women's results continued after 5 hours. In a study in which the participants were shortand long-distance elite runners, participants were given a progressive step test that continued until exhaustion before and after 6-month intensive training periods. Although not statistically significant, MMP9 levels were higher in the initial period in the short-distance group. Also, MMP9 levels were found 
significantly higher immediately after acute exercise in the final period. Although there were increases after exercise, the differences between the MMP9 results in both periods in the long-distance group were not significant [25]. It was observed that changes in MMP level responses to acute exercise were stronger in the first few hours. The type and duration of exercise can also be an important factor that infuences these changes. Although the exercise duration in the current study was not very long, the fact that the YoYo IR1 test continued until the participants were exhausted was effective in observing the activation in MMP9 and TIMP1. Acute intense exercise has an inflammatory effect, it may be possible to explain the increases with the reaction caused by this effect.

Considering the chronic effects of exercise on enzyme activities, Filipović, Gopčević [26] investigated the effects of a 12-week exercise program on serum MMP9 and TIMP1 activity in postmenopausal patients with osteoporosis. This exercise program included aerobic, resistance and balance exercises. After 12 weeks, MMP9 enzyme activity and the MMP9/TIMP1 ratio decreased and TIMP1 enzyme activity increased significantly. The athletic group in the current study had lower MMP9 levels compared with the sedentary group. It is possible to state that they had to do exercises for both the aerobic and anaerobic system due to the training of their branch. In this case, it can be emphasized that the basal levels in this study are compatible with the study of Filipović et al. Regular aerobic training can provide antiinflammatory responses and decrease MMP9 levels [2]. However, in the present study, basal TIMP1 levels and MMP9/TIMP1 ratios were not statistically different between the athletic and sedentary groups. Buyukyazi, Ulman [27] found no significant effect of 8-week walking (with approximately $62 \%$ maximum heart rate reserve) on MMP9 and TIMP1 levels and MMP9/TIMP1 ratio in healthy postmenopausal women. In studies investigating the chronic effects of exercise, factors such as the exercise history of the participants, the components of the applied chronic exercise, and the nutrition habits of participants may cause inconsistent results.

In the present study, no homozygous TT genotype group was created because none of the participants had the TT genotype for the MMP9-1562 C/T polymorphism. In a study conducted with 177 healthy men, the allele frequencies were determined as $90 \%$ for the $\mathrm{C}$ allele and $10 \%$ for the $T$ allele, similar to the present study and plasma pro-MMP9 levels had no significant differences among MMP9-1562 C/T polymorphism genotype groups in healthy men [28]. Fiotti, Deiuri [29] found that body composition and strength parameters improved after long-term physical exercise applied to elderly women, and these improvements were associated with certain MMP polymorphisms, including MMP9. In the current study, the increase in AST level response to Yo-Yo IR1 was higher in athletes with the CT genotype than in sedentary individuals with the CT genotype. This finding suggests that athletes with the CT genotype are affected more by the muscle damage consequences of acute exercise than sedentary individuals with the CT genotype.

Studies on the MMP9 and TIMP1 gene polymorphisms in athletes are quite limited. Tabatabaee, Heidari [30] studied Malaysian males with hypertension and healthy individuals and investigated specific gene polymorphisms including TIMP1 $372 \mathrm{~T} / \mathrm{C}$. Allele frequencies of this polymorphism showed a significant difference between the two groups. According to the findings of this study, the TIMP1 372 T/C 
polymorphism had a genetic role in hypertension. Polina, Araújo [31] studied 300 individuals with chronic heart disease and 304 healthy individuals and found that the genotype and allele frequencies of the TIMP1 372 T/C polymorphism in the patient group were not different from the healthy group. When the findings of the current study were evaluated in terms of atherosclerosis risk factors, it can be stated that the individuals with the $\mathrm{C}$ allele are in the higher risk group than individuals with the $T$ allele as a result of the differences in TC and LDL-C levels in the allele groups. At the same time, the $C$ allele triggers the acute LDL-C increase after acute exercise.

The number of participants in terms of the polymorphism may appear lower than in population studies in the literature because this study is an experimental study. The TIMP1 gene was evaluated on a single allele because all participants were male. However, to the best of our knowledge, this is the first study to investigate these genetic polymorphisms' roles on MMP9 and TIMP1 level responses to acute exercise in specific groups of athletes and sedentary individuals. This research will serve as a basis for future studies; further experimental investigations are needed to estimate the role of these polymorphisms on MMPs and TIMPs. From this point of view, orienting individuals to sports branches that are genetically suitable and thus preventing serious injuries could be provided.

\section{Conclusion}

The results of the current study show that MMP9 and TIMP1 are involved in remodelling steps after acute exercise in sedentary and athletic males. Acute post-exercise responses of MMP9 and TIMP1 are similar in athletes and sedentary individuals. Basal MMP9 levels are lower in atlhletic group and this result may have been caused by the chronic training effects that the athletic group exposed to. MMP9-1562 C/T and TIMP1 372 T/C polymorphisms are not associated with this enzyme and its inhibitor.

\section{Declarations}

Acknowledgement: We acknowledge to scientific research projects coordination of Ege University.

Funding: This study was supported financially by scientific research projects coordination of Ege University (The Project no: TDK-2019-20275).

Availability of data and material: The datasets of the present study are not publicly available due to privacy protection.

\section{Code availability: Not applicable}

Authors' contributions: All authors contributed to the study design. Material preparation and data collection were performed Merve Koca Kosova, Faruk Turgay, Sercin Kosova, Aykut Eren Canüzmez; analysis were performed by Faruk Turgay, Oya Yigittürk, Semih Aşıkovalı, Burak Durmaz. The first draft of the manuscript was written by Merve Koca Kosova and all authors commented on previous versions of 
the manuscript. All authors read and approved the final manuscript. The authors declare that all data were generated in-house and that no paper mill was used.

\section{Compliance with ethical standards}

Conflicts of interest: No conflict of interest is declared.

Ethics approval: . The research was approved by Ege University Faculty of Medicine Clinical Research Ethics Committee (Approval number: 18-7.1/49).

Consent to participate: All participants were informed about the study and written informed consent was obtained before taking the measurements.

\section{References}

1. Hynes RO (2009) The extracellular matrix: not just pretty fibrils. Science 326(5957):1216-1219. https://doi.org/10.1126/science.1176009

2. Presti RL, Hopps E, Caimi G (2017) Gelatinases and physical exercise: a systematic review of evidence from human studies. Medicine 96(37). https://doi.org/10.1097/MD.0000000000008072

3. Visse R, Nagase H (2003) Matrix metalloproteinases and tissue inhibitors of metalloproteinases: structure, function, and biochemistry. Circulation research 92(8):827-839. https://doi.org/10.1161/01.RES.0000070112.80711.3D

4. Kim J, Lee J (2016) Matrix metalloproteinase and tissue inhibitor of metalloproteinase responses to muscle damage after eccentric exercise. J Exerc Rehabil 12(4):260. https://doi.org/10.12965/jer.1632640.320

5. Wu ZS, Wu Q, Yang JH, Wang HQ, Ding XD, Yang F et al (2008) Prognostic significance of MMP-9 and TIMP-1 serum and tissue expression in breast cancer. Int J Cancer 122(9):2050-2056. https://doi.org/10.1002/ijc.23337

6. Ramella M, Boccafoschi F, Bellofatto K, Follenzi A, Fusaro L, Boldorini R et al (2017) Endothelial MMP-9 drives the inflammatory response in abdominal aortic aneurysm (AAA). Am J Transl Res 9(12):5485-5495

7. Brew K, Nagase H (2010) The tissue inhibitors of metalloproteinases (TIMPs): an ancient family with structural and functional diversity. Biochim Biophys Acta 1803(1):55-71. https://doi.org/10.1016/j.bbamcr.2010.01.003

8. Murphy G (2011) Tissue inhibitors of metalloproteinases. Genome biology 12(11):233. https://doi.org/10.1186/gb-2011-12-11-233

9. Mackey AL, Donnelly AE, Swanton A, Murray F, Turpeenniemi-Hujanen T (2006) The effects of impact and non-impact exercise on circulating markers of collagen remodelling in humans. Journal of sports sciences 24(8):843-848. https://doi.org/10.1080/02640410500231470 
10. Zaidi H, Byrkjeland R, Njerve IU, Åkra S, Solheim S, Arnesen H et al (2019) Effects of exercise training on markers of adipose tissue remodeling in patients with coronary artery disease and type 2 diabetes mellitus: sub study of the randomized controlled EXCADI trial. Diabetol Metab Syndr 11(1):1-9. https://doi.org/10.1186/s13098-019-0508-9

11. Gumpenberger M, Wessner B, Graf A, Narici MV, Fink C, Braun S et al (2020) Remodeling the Skeletal Muscle Extracellular Matrix in Older Age-Effects of Acute Exercise Stimuli on Gene Expression. Int J Mol Sci 21(19):7089. https://doi.org/10.3390/ijms21197089

12. Rahimi S, Sayad A, Moslemi E, Ghafouri-Fard S, Taheri M (2017) Blood assessment of the expression levels of matrix metalloproteinase 9 (MMP9) and its natural inhibitor, TIMP1 genes in Iranian schizophrenic patients. Metab Brain Dis 32(5):1537-1542. https://doi.org/10.1007/s11011-0170043-z

13. Jacob M, Badier-Commander C, Fontaine V, Benazzoug Y, Feldman L, Michel J (2001) Extracellular matrix remodeling in the vascular wall. Pathol Biol 49(4):326-332. https://doi.org/10.1016/S03698114(01)00151-1

14. Madden MC, Byrnes WC, Lebin JA, Batliner ME, Allen DL (2011) Plasma matrix metalloproteinase-9 response to eccentric exercise of the elbow flexors. Eur J Appl Physiol 111(8):1795-1805. https://doi.org/10.1007/s00421-010-1806-y

15. Kim J, Lee J (2020) Plasma MMP-9, TIMP-1, and TGF- $\beta 1$ Responses to Exercise-Induced Muscle Injury. Int. J Environ Res Public Health 17(2):566. https://doi.org/10.3390/ijerph17020566

16. Welsh M, Allen D, Byrnes W (2014) Plasma matrix metalloproteinase-9 response to downhill running in humans. Int J Sports Med 35(05):363-370. https://doi.org/10.1055/s-0033-1353212

17. Koskinen S, Höyhtyä M, Turpeenniemi-Hujanen T, Martikkala V, Mäkinen T, Oksa J et al (2001) Serum concentrations of collagen degrading enzymes and their inhibitors after downhill running. Scand $J$ Med Sci Sports 11(1):9-15. https://doi.org/10.1034/j.1600-0838.2001.011001009.x

18. Reihmane D, Jurka A, Tretjakovs P, Dela F (2013) Increase in IL-6, TNF-a, and MMP-9, but not sICAM1, concentrations depends on exercise duration. Eur J Appl Physiol 113(4):851-858. https://doi.org/10.1007/s00421-012-2491-9

19. Zhang B, Ye S, Herrmann S-M, Eriksson P, de Maat M, Evans A et al (1999) Functional polymorphism in the regulatory region of gelatinase $B$ gene in relation to severity of coronary atherosclerosis. Circulation 99(14):1788-1794. https://doi.org/10.1161/01.CIR.99.14.1788

20. Hinterseher I, Krex D, Kuhlisch E, Schmidt KG, Pilarsky C, Schneiders W et al (2007) Tissue inhibitor of metalloproteinase-1 (TIMP-1) polymorphisms in a Caucasian population with abdominal aortic aneurysm. World J Surg 31(11):2248-2254. https://doi.org/10.1007/s00268-007-9209-x

21. Buraczynska K, Kurzepa J, Ksiazek A, Buraczynska M, Rejdak K (2015) Matrix metalloproteinase-9 (MMP-9) gene polymorphism in stroke patients. Neuromol Med 17(4):385-390. https://doi.org/10.1007/s12017-015-8367-5

22. Lorente L, Martín M, Plasencia F, Solé-Violán J, Blanquer J, Labarta L et al (2013) The 372 T/C genetic polymorphism of TIMP-1 is associated with serum levels of TIMP-1 and survival in patients 
with severe sepsis. Crit Care 17(3):R94. https://doi.org/10.1186/cc12739

23. Bangsbo J, laia FM, Krustrup P (2008) The Yo-Yo intermittent recovery test. Sports Med 38(1):37-51. https://doi.org/10.2165/00007256-200838010-00004

24. Astill BD, Katsma MS, Cauthon DJ, Greenlee J, Murphy M, Curtis D et al (2017) Sex-based difference in Achilles peritendinous levels of matrix metalloproteinases and growth factors after acute resistance exercise. J Appl Physiol 122(2):361-367.

https://doi.org/10.1152/japplphysiol.00878.2016

25. Suhr F, Rosenwick C, Vassiliadis A, Bloch W, Brixius K (2010) Regulation of extracellular matrix compounds involved in angiogenic processes in short-and long-track elite runners. Scand J Med Sci Sports 20(3):441-448. https:// doi.org/10.1111/j.1600-0838.2009.00960.x

26. Filipović T, Gopčević K, Dimitrijević S, Hrković M, Backović A, Lazović M (2020) Effects of 12-Week Exercise Program on Enzyme Activity of Serum Matrix Metalloproteinase-9 and Tissue Inhibitor of Metalloproteinase-1 in Female Patients with Postmenopausal Osteoporosis: A Randomized Control Study. BioMed Research International https://doi.org/10.1155/2020/9758289

27. Buyukyazi G, Ulman C, Taneli F, Aksoy D, Tikiz H, Ari Z (2008) The effects of an 8-week walking program on serum lipids, circulation matrix metalloproteinase-9 and tissue inhibitor of metalloproteinase-1 in post-menopausal women. Turkish journal of biochemistry 33(4):154-162

28. Demacq C, Vasconcellos VB, Marcaccini AM, Gerlach RF, Silva WA, Tanus-Santos JE (2008) Functional polymorphisms in the promoter of the matrix metalloproteinase-9 (MMP-9) gene are not linked with significant plasma MMP-9 variations in healthy subjects. Clin Chem Lab Med 46(1):5763. https://doi.org/10.1515/CCLM.2008.014

29. Fiotti N, Deiuri E, Altamura N, Moretti M, Toigo G, Giansante C (2009) Body composition and muscular strength changes after moderate activity: association with matrix metalloproteinase polymorphisms. Arch Gerontol Geriatr 49:83-94. https://doi.org/10.1016/j.archger.2009.09.016

30. Tabatabaee FAG, Heidari F, Khazaei S, Etemad A, Ismail P (2018) Association of MMP-1, 9, 12 and TIMP-1 gene polymorphisms in Malaysian male hypertensive subjects. Biomed Res 29(9):17341742. https://doi.org/10.4066/biomedicalresearch.29-17-470

31. Polina ER, Araújo RRCV, Sbruzzi RC, Biolo A, Rohde LE, Clausell N et al (2018) Relationship of polymorphisms in the tissue inhibitor of metalloproteinase (TIMP)-1 and-2 genes with chronic heart failure. Scientific reports 8(1):1-8. https://doi.org/10.1038/s41598-018-27857-5

\section{Tables}

Due to technical limitations, the tables are only available as a download in the supplemental files section.

\section{Supplementary Files}

This is a list of supplementary files associated with this preprint. Click to download. 
- Tables.docx

Page $12 / 12$ 